\title{
Lupus nephritis: Update on aetiopathogenesis and controversies in classification
}

\section{Pant $\mathrm{AD}^{1}$}

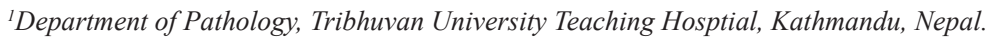

\section{Keywords:}

Systemic lupus erythematosus; kidney;

Immune complex

\begin{abstract}
Abstract: Systemic Lupus Erythematosus; a chronic autoimmune disease; is characterized by loss of tolerance against its own antigens and leads to production of autoantibodies and causes formation and deposition of immune complexes in different organs. Recent articles have been trying to unravel the mysteries of SLE. Different theories that have been proposed for the aetiopathogenesis of SLE are a)The circulating immune complex theory, b) The direct binding to endogenous renal antigens theory, and c) binding of antibody to antigens that were previously 'planted' into the kidney.
\end{abstract}

\section{INTRODUCTION}

Systemic Lupus Erythematosus (SLE) is a prototypical chronic autoimmune disease. It is characterised by loss of tolerance against its own antigens and leads to activation of immune system leading to production of autoantibodies. This leads to formation and deposition of immune complexes in different organs, causing inflammation at those multiple sites. The kidney is one of the common organs in which there is deposition of these immune complexes and it leads to lupus nephritis. It is characterised by hematuria, proteinuria, and eventually renal failure if the disease progresses.

The aetiology of SLE is usually referred to as unknown. However, recent articles have been trying to unravel

\section{Correspondence:}

Dr. Anil Dev Pant MBBS, MD

Department of Pathology

Tribhuvan University Teaching Hosptial, Kathmandu, Nepal.

Email:dradpa@gmail.com the mysteries of SLE. It is important to understand the aetiopathogenesis in order to develop newer and more effective treatment methods for these patients. ${ }^{1}$

\section{AETIOPATHOGENESIS OF LUPUS NEPHRITIS}

Main mechanisms in autoantibody production is the breakdown of B- and T-cell tolerance, increased amount of auto-antigens and defects in clearance of apoptotic cells. Different theories have been proposed and are listed below: ${ }^{2}$

1) The circulating immune complex theory is not as important as was initially thought. In this mechanism, immune complexes are passively trapped, most commonly in the mesangium. Even though they may be phagocytosed, their brief presence may stimulate the mesangial cells to produce mesangial matrix.

2) The direct binding to endogenous renal antigens theory is when circulating antibodies bind to renal antigens. 


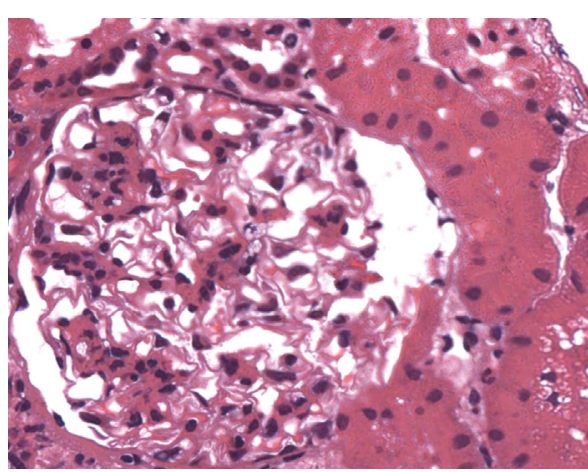

Figure 1: Mesangial Lupus Nephritis, Class II showing mesangial cell proliferation and increased mesangial matrix

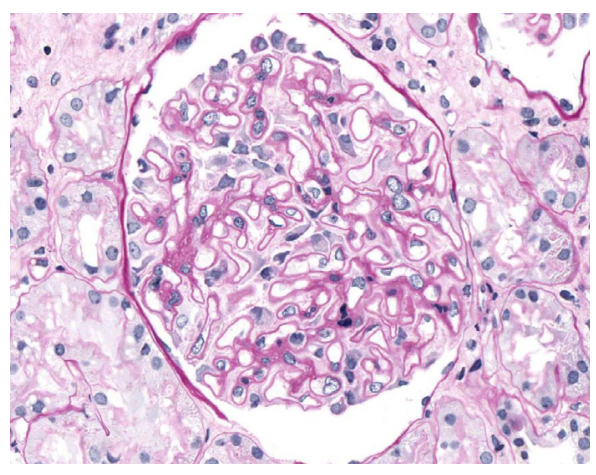

Figure 3: Lupus Nephritis Class V with thickening of the glomerular basement membrane, stained with PAS stain

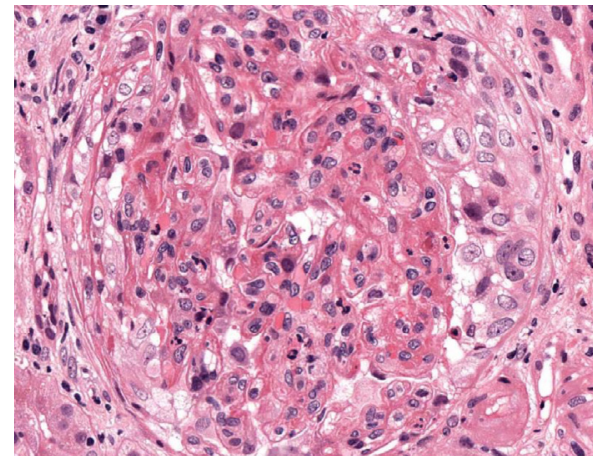

Figure 2: Lupus Nephritis Class IV with endocapillary and mesangial proliferation. Note a crescent almost surrounding the whole glomerulus

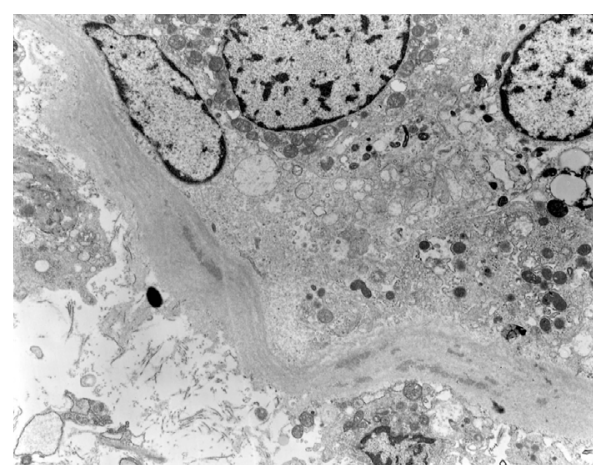

Figure 4: Lupus Nephritis, showing presence of deposits in the tubular basement membrane, seen on electron microscopy
3) Another method is by binding of antibody to antigens that were previously 'planted' into the kidney. These antigens were probably derived from dead cells, and mostly nucleosomes are implicated.

It is the latter 2 mechanisms where most of the current evidence points towards. The antigens are usually of the IgG type, fix complement, and are highly crossreactive. Deposition of antibody alone is not sufficient for development of disease. Complement components have been found in renal biopsies along with complement activation products observed in sera as well. Deficiencies in early complements of classical pathway, i.e. C1q, C4 and $\mathrm{C} 2$ in patients have also been implicated in the development of lupus. ${ }^{3}$

The planted nucleosome antigen hypothesis has been gaining favour as the mechanism by which lupus nephritis occurs. The nucleosomes may originate from circulating or intraglomerular apoptotic cells and are associated with glomerular basement membrane or mesangial matrix. It has been suggested that nucleosomes are trapped in by glomerular components such as type IV collagen, heparan sulfate and other negatively charged particles. Laminin could be an intrinsic ligand of the glomerular basement membrane, and supposedly binds to nucleosomes with high affinity. $^{4-9}$
Because anti-nucleosome antibodies may be positive when anti-dsDNA (anti double stranded DNA) is negative, these antibodies are especially important in those cases which clinically resemble lupus but are anti-dsDNA. ${ }^{10}$

\section{Extra-renal pathologic mechanisms}

How do nuclear antigens get exposed during apoptosis? Under normal circumstances, these antigens are rapidly cleared, inhibiting interactions with $\mathrm{T}$ cells. However, in selected patients, there may be inherited defects in mechanisms that ensure low levels of chromatin in extracellular compartment and removal of these dead cells by apoptosis. This leads to degeneration of its components which help the body to differentiate it from viral nucleic acids. ${ }^{10,11}$

There may be persistent activation of dendritic cells and B-cells; this can even overcome the anergy of auto-reactive B cells. Lymphocytic mitogens like B-cell activating factor (BAFF) and a proliferation-inducing ligand (APRIL) are secreted. They promote B-cell maturation and plasma cell survival (a potential therapeutic target).

Finally, environmental triggers include viral and bacterial infections. Ultraviolet light causes death of keratinocytes and causes increase in extracellular material. Drug induced 
SLE causes unmasking of endogenous nucleic acids. Hormones stimulate immune-regulatory pathways leading to enhanced autoimmunity.

Thus, there is an initial clonal expansion of lymphocytes which causes production of auto-antibodies and immune complex deposition. Environmental factors can further aggravate the process.

\section{Intra-renal pathologic mechanisms}

The traditional concept that circulating immune complexes passively deposit in the kidney has been challenged by the recent evidence that they may actually be formed by binding to nucleosomes from renal cells.

Cytotoxic T cells, TH17 T cells and B cells are present in the kidney in lupus nephritis. Macrophages may also contribute to the progression of the disease.

Limitations in understanding the mechanism of lupus have led to limited treatment modalities. It is also critical to understand the role of B lymphocytes in immune system. B lymphocytes are part of the adaptive immune system and have roles of secreting immunoglobulins and also act as antigen presenting cells to T cells. Bhat and Radhakrishnan focused their study on the role of B lymphocytes in lupus nephritis. With better understanding of B lymphocytes dysfunction, they studied newer treatment methods that target Bcells. The therapies act by causing B cell depletion, blockade of $\mathrm{T}$ cell co-stimulation or blockade of $\mathrm{B}$ cell stimulation and are showing promise but need to be evaluated further. ${ }^{12}$

\section{Site of deposition of immune complexes:}

The sites of deposition of immune complexes in different parts of glomeruli depend on different factors: 1) circulating levels of antigen/antibody, 2) specificity, 3) avidity, 4) size, and 5) charge. Location of immune deposits also may influence the main effector mechanism. ${ }^{13}$

Experimental models have shown that small cationic immune complexes deposit in the sub-epithelial space, where they can cause proteinuria by causing injury to podocytes. If deposits are in sub-epithelial space, the membrane attack complex which is generated by complement activation injures the endothelial cells - this leads to alteration in glomerular barrier function and significant proteinuria (inflammatory component is absent because the basement membrane prevents inflammatory cells from reaching the deposits).

Intermediate sized complexes may be deposited in the mesangium, where initial clearance may take place; later, if deposition continues, it may cause glomerular disease. Larger immune complexes may deposit in the sub-endothelial space where they come in contact with inflammatory mediators through the endothelial pores, leading to recruitment and activation of leukocytes. If the immune deposit is located near vasculature, i.e. in the sub-endothelial or mesangial space, inflammatory cells are recruited and cause injury. ${ }^{14}$

\section{ISN/RPS 2003 CLASSIFICATION OF LUPUS NEPHRITIS ${ }^{15-18}$}

\section{Class I: Minimal mesangial lupus nephritis}

The normal category has been removed and this term is used to represent lupus nephritis with normal appearing glomeruli but presence of mesangial deposits by immunofluorescence.

\section{Class II: mesangial proliferative lupus nephritis}

This category is characterised by mesangial proliferation seen in light microscopy and presence of mesangial deposits in immunofluorescence. Even rare sub-endothelial or sub-epithelial deposits by immunofluorescence or electron microscopy are permissible. However, presence of sub-endothelial deposits by light microscopy warrants upgrading to a higher class, i.e III or IV. (fig. 1)

\section{Class III and IV: focal and diffuse lupus nephritis}

Both these classes are actually a continuum of the disease, with the differences being only in the severity and distribution. Class III lesions are typically segmental and the endocapillary proliferation involves less than 50\% of the glomeruli. Class IV lesions show endocapillary proliferation involving $50 \%$ or more of the glomeruli. (fig. 2) Class IV lesions have been subcategorised as IV-S (if proliferation is only segmental) and IV-G (if it is global and involves equal to or more than $50 \%$ of the glomerular tuft). Based on activity and chronicity indices, they can be further subdivided into purely active (A), purely chronic (C), or mixed type (A/C).

The term proliferative has been removed because not all III and IV lesions will show proliferative features. Other lesions that lack endocapillary proliferation which can be within this group include extra capillary proliferations/ crescents, membranoproliferative features, and in cases where there is no endocapillary proliferation but presence of sub-endothelial wire loop deposits. Even global or segmental sclerosis has been included in this category as chronic lesions and they are thought to be the sequelae of previous active lupus nephritis.

A controversy exists about the sub-classification into IV-S and IV-G. IV-S patients were initially thought to have more fibrinoid necrosis, less immune deposits and worse prognosis. This lead to a hypothesis that there were different mechanisms between the two sub-classes. Supporting this hypothesis, initial studies showed difference in survival in the two sub-classes. However, other more recent 
studies have challenged this theory because there were no differences shown in survival. Hence raises the question of the need of subdivision of class for into IV-G and IV-S..$^{19-21}$

\section{Class V: membranous lupus nephritis}

There is presence of segmental or global sub epithelial immune deposits. There may also be mesangial proliferation and mesangial deposits seen on immunofluorescence. (fig. 3 \& 4) If features of class III or IV lupus are present, at least $50 \%$ sub epithelial deposits in at least $50 \%$ of the glomeruli are required in order to give the additional diagnosis of class V (i.e. III $+\mathrm{V}$, or IV + V).

\section{Class VI: advanced sclerosing lupus nephritis}

The is the late stage in which more than $90 \%$ of the glomeruli are globally sclerotic. There should also be no evidence of any ongoing activity.

\section{TUBULOINTERSTITIAL LESIONS}

During reporting, tubulointerstitial lesions should be mentioned as well. These include tubular atrophy, interstitial fibrosis and interstitial inflammation. Immune deposits have been seen by light microscopy and/or electron microscopy in peritubular regions. The degree of inflammation and fibrosis corresponds to the impairment of renal function and progression of lupus nephritis.

\section{VASCULAR LESIONS}

Immune deposits are seen around vessel walls, especially in class IV lupus nephritis. These deposits are detected by immunofluorescence or electron microscopy. In few patients, large deposits cause intimal expansion and may cause narrowing or even blockage of the lumina of blood vessels. Because an inflammatory component is lacking, the term lupus vasculopathy is used.

When there is association with fibrinoid necrosis with leukocyte infiltration of the vessel wall, this entity is termed lupus vasculitis - a true picture of vasculitis is present. This entity is even rarer than vasculopathy.

Both these aforementioned lesions are associated with a worse prognosis. ${ }^{22,23}$

\section{LUPUS PODOCYTOPATHY}

These are cases of SLE presenting with nephrotic syndrome and have minimal change disease or focal segmental glomerulosclerosis like features. Only minimal mesangial immune deposits are seen in these cases, and the extensive foot process effacement is not explained. Kraft et al concluded that nephrotic syndrome can occur in SLE without features of class $\mathrm{V}$ glomerulonephritis (peripheral capillary wall deposits), and these cases should be referred to as 'lupus podocytopathy'. These patients also undergo rapid remission after treatment with steroids, similar to typical minimal change disease patients..$^{24,25}$

\section{CONCLUSION}

In closing, it is quite evident that lupus nephritis is a complex disease with unexplained questions in aetiopathogenesis, despite such extensive research. More studies need to be conducted in order to shed more light on the process, so that more effective treatment modalities can be developed. In addition, the ISN/RPS classification, though much more mature and reproducible than the previous ones formulated by WHO, still has some controversies, especially in class IV-G or IV-S which need to be resolved. This will probably be done in a future classification, which is now due for an update.

\section{REFERENCES}

1. Agati VD. Renal disease in Systemic lupus erythematosus, mixed connective tissue disease, Sjogren's syndrome and Rheumatoid arthritis. In: Jennetts JC, Olson JL, Schwartz MM, Silva FG, eds. Heptinstall's Pathology of the Kidney. Lippincott Williams and Wilkins, 2007.pp518-61.

2. Walman M, Madaio MP. Pathogenic autoantibodies in lupus nephritis. Lupus 2005;14:19-24. Crossref

3. Olin AI, Morgelin M, Truedsson L, Sturfelt G, Bengtsson AA. Pathogenic Mechanisms in Lupus Nephritis. Arthritis and Rheumatology 2014;66:397-406. Crossref

4. Dieker JW, Van der Vlag J, Berden JH. Deranged removal of apoptotic cells: its role in the genesis of lupus. Nephro Dial Transplant 2004;19:282-5. Crossref

5. Berden JH, Grootscholten C, Jurgen WC, van der Vlag J. Lupus nephritis: a nucleosome waste disposal defect? J Nephrol 2002;15:110.

6. Chai Q, Kpag S, Miner JH, Nyenyoard JR, Chai S, Wogensen L. TGF1 induces aberrant laminin chain and collagen type IV isotope expression in the glomerular basement membrane. Nephron ExpNephrol 2003;94:123-6. Crossref

7. Mjelle JE, Rekvig OP, Fenton KA. Nucleosomes possess a high affinity for glomerular laminin and collagen IV and bind nephritogenic antibodies in murine lupus-like nephritis. Ann Rheum Dis 2007;66:1661-8. Crossref

8. Mortensen ES, Rekvig OP. Nephritogenic potential of anti-DNA antibodies against necrotic nucleosomes. J Am SocNephrol 2009;20:696-704. Crossref

9. Gaipl US, Voll RE, Sheriff A, Franz S, Kalden JR, Herrmann M. Impaired clearance of dying cells in systemic lupus erythematosus. Autoimmun Rev 2005;4:189-94. Crossref

10. Agrawal S. Lupus nephritis: An update on pathogenesis. J Indian RheumatolAssoc 2004;12:11-5.

11. Lech M, Anders HJ. The Pathogenesis of Lupus Nephritis. J Am SocNephrol 2013;24:1357-66. Crossref

12. Bhatt $\mathrm{P}$ and Radhakrishnan. B lymphocytes and lupus nephritis: New insights into pathogenesis and targeted therapies. Kid Int 2008;73:261-8. Crossref

13. Seshan SV, Jennette C. Renal disease in systemic lupus erythematosus with emphasis on classification of lupus glomerulonephritis. Arch Pathol Lab Med 2009;133:233-48. PMid:19195967

14. Oates J, Gilkeson GS. Mediators of injury in lupus nephritis. CurrOpinRheumatol 2002;14:498-503. Crossref 
15. Weening JJ, Agati VD, Schwartz MM et al. The classification of glomerulonephritis in systemic lupus erythematosus revisited 2004;15:835-6.------check

16. Markowitz GS, Agati VD. Classification of lupus nephritis. Curt OpinNephrolHypertens 2009;18:220-5. Crossref

17. Furness PN, Taub N. Interobserver reproducibility and application of the ISN/RPS classification of lupus nephritis: A UK-wide study. AM J SurgPathol 2006;30:1030-5. Crossref

18. Hiramatsu N, Kuroiwa T, Ikeuchi H, et al. Revised classification of lupus nephritis is value in predicting outcome with an indication of the proportion of glomeruli affected by chronic lesions. Rheumatol 2008;47:702-7. Crossref

19. Mittal B, Jurwitz S, Rennke H, Singh AK. New subcategories of class IV lupus nephritis: are there clinical, histologic, and outcome differences? Am J Kidney Dis 2004;44:1050-9. Crossref

20. Hill GS, Delahousse M, Nochy D, Bariety J. Class IV-S vs class IV-G lupus nephritis: clinical and morphological differences suggesting different pathogenesis. Kidney Int 2005;68:2288-97. Crossref

21. Schwartz MM, Korbet SM, Lewis EJ. The prognosis and pathogenesis of severe lupus glomerulonephritis. Nephrol Dial Transplant 2008; 23: 1298-1306 Crossref
22. Banfi G, Bertani T, Boeri V et al. Renal vascular lesions as a marker of poor prognosis in patients with lupus nephritis. Am J Kidney Dis 1991;18:240-8. Crossref

23. Seshan SV. Lupus Vasculopathy and vasculitis: what is the difference and when do they occur? Patrol Case Rev 2007;12:214-21. Crossref

24. Dube GK, Markowitz GS, Radhakrishan J, et al. Minimal change disease in systemic lupus erythematous. ClinNephrol 2002;40:117984.

25. Kraft SW, Schwartz MM, Korbet SM, Lewis EJ. Glomerular podocytopathy in patients with systemic lupus erythematous. J Am SocNephrol 2004;16:175-9. Crossref 